\title{
The Study of Relationship between the Awareness Level of Management Tasks with Self-efficacy in Sport Managers of Isfahan City
}

\author{
Mohammadjavad GHAZAEI ${ }^{1}$, Mohammad KHAKI ${ }^{2}$, Somayyeh NADERI ${ }^{3}$, Saeed SHAMS ${ }^{4}$ \\ ${ }^{1}$ M.A of Master of Science-Sport Management, Physical Education Trainer; Islamic Azad University \\ Mobarakeh branch, Iran \\ ${ }^{2}$ Master of Science-Physical Education, Physical Education Trainer; M.A of kharazmi University Tehran \\ ${ }^{3}$ M.A of University Payamenoor Tehran, Master of Science-Physical Education, Physical Education Trainer \\ ${ }^{4}$ M.A student of Payamenoor Tehran
}

\begin{abstract}
Managers should have thorough knowledge about the management tasks and also more commitment toward their activities in order to be successful, understanding such factors have great value for promoting the organizational goals. The main purpose of the present paper is to examine the relationship of awareness of managers regarding their management tasks with self-efficacy in sport managers of Isfahan city. The research method is correlative-descriptive and the statistical sample is 91 individuals between 120 senior sport managers of Isfahan that were selected based on Cohen and Cochran formula through random sampling method. The data were gathered via research based questionnaires about awareness toward management tasks and Sherer self-efficacy questionnaire (1982). The reliability of these two questionnaires was confirmed according to Cronbach's Alpha 0.74 and 0.78 , respectively, after defining the face and content validity by the expertise. The obtained information was analyzed based on descriptive and inferential statistical methods, Kolmogorov-Smirnov test, Levene Test, Pearson correlation tests and one-variable t-test. The significance level for testing the hypothesis was considered as $P \leq 0 / 05$. The study of the findings showed an average level of awareness toward the management tasks and high level of self-efficacy in sport managers and a significant relationship between awareness of management tasks with self-efficacy.
\end{abstract}

Keywords: Management Tasks, Self-efficacy, Sport Managers.

\section{Introduction}

Managers should be aware with the developments and update methods in the world continuously, revise their aims and consequences and coordinate the organizations with the universal requirements; so that could equip all their material and intellectual forces, initiatives and talents within performing their tasks and take steps to the success. Utilizing the logical and known scientific methods require the scholar statesmen prepared with art and science. New technologies in the field of management knowledge and leadership of the organizations have changed the living conditions. The organizations become extensive and complex and require powerful policy makers, effective decision makings and dominant technical tools besides strong mentality and great thoughts. In the world markets, the value of scientist, humanist and modernism managers exceeded from financial credit and technical tools (4).

It is obvious that the knowledge of management, especially in the field of physical education and sport could advance in its way toward success by obtaining feedbacks in 
different social, political, cultural and psychological fields. Today, deficiency in a system is less addressed to individual, group or hardware reasons, but also an insufficiency could be referred more to management plans of a system, also the reason of success or failure of bodies in a system is related to difference in their management methods (3).

Managers should have a thorough awareness regarding their management tasks based on the organizational goals, so that could lead the organization to the pre-determined goals. According to the wide range of sport activities and human resource engaged in this area, the awareness of managers about the update knowledge of management is considered as an essential issue in advancing the organizational goals (2). Henry Fayol considered six primary tasks for the managers, including Planning, organization, Command, Coordination, Decision making and Control. The management tasks are based on the theory of Henry Fayol in the present study (1). Although the tasks of a manager should be revealed in practice, but does a theoretical mind regarding these six primary tasks that have been defined mostly by the researchers in the field of management could be effective on psychological areas that nowadays are considered as attractive areas related to management science?

All the managers in small business enterprises or enormous business and sport organizations weather in general management level or in specific areas have the responsibility to fulfill the mentioned tasks of Planning, Organization, Command, Coordination, Decision making and Control (2). These tasks exist in organizations and sport managers specially in sport organizations as the main trustees of sport in the country that are considered as the common tasks of all the managers, performing these tasks in mentioned organizations would lead to improvement of sport status in our country.

Nearly all people could recognize that which goals they want to accomplish, which items they want to change and which areas want to reach. Yet, most of people accept that implementation or actualization of such programs is not an easy task. Bandura discovered that self-efficacy of each individual has a major role in his/her view toward the goals, tasks and challenges. The persons with strong self-efficacy consider the challenging issues as the problems that should be overcome. Also, they have a deeper interest in the activities that they are engaged. Such characters have greater commitment toward their interests and activities and overcome rapidly with the sense of despair and frustration.

In contrast, people with weak self-efficacy avoid challenging tasks and they believe that difficult circumstances and tasks are out of their ability and capability. Also, they focus on their personal failures and negative consequences and lose their confidence toward their abilities and capabilities (7).

The concept of self-efficacy has a short history that begins with Bandura's works in 1977. He has addressed this issue in his paper titled "Self-efficacy: Toward a Unifying Theory of Behavioral Change" (11).

Self-efficacy is different regarding the way of thinking and action of people (8). In other words, self-efficacy refers to the perceived ability of the individual according to specific 
circumstances and related to the judgment of people toward their ability in performing a task or adjustment to a specific circumstance. Self-efficacy applied to the sense of selfrespect, self-worth and sense of sufficiency and efficiency toward the life (7). The beliefs of individuals regarding their ability to handle different circumstances are referred to selfefficacy.

Self-efficacy affects stress, psychological pressures and depression resulting from threatening circumstances. People with strong self-efficacy could decrease their psychological pressure in stressful circumstances. But people with weak self-efficacy experience high anxiety in controlling the threats, expand their lack of self-efficacy and consider many environmental aspects as dangerous and threatening that result in higher stress and psychological pressure. In fact, increase of self-efficacy lead to health improvement indirectly and such personalities have greater skills in solving the problems (13).

Many factors are effective on the success of an organization. Self-efficacy as a cognitive factor could help the managers and smooth the way of success. Therefore, understanding such factors and the ways to strengthen them have great importance in advancing the organization's goals (5).

It seems that fewer studies have attended to the subject of awareness level of managers regarding their tasks and its effect considering cognitive variables specifically self-efficacy in sport managers society, addressing this subject among the sport managers of Isfahan city is the main focus of the authors of the present paper. So, according to the importance of management role and manager's tasks in the organizations specifically in sport organizations and also awareness of these tasks and their relationship with self-efficacy of managers, the present paper aims to study the relationship between awareness of management tasks (Planning, Organization, Command, Coordination, Decision making and Control) with self-efficacy among sport managers of Isfahan city. The main research question is: if there is any relationship between awareness of management tasks with selfefficacy? In other words, if the self-efficacy level increase with increase in awareness level of managers about their management tasks.

According to all mentioned subjects, the main focus of the authors is referred to prove the relationship of one comparatively new cognitive area named as "self-efficacy" with sport management that in functional domain result in more study by the managers regarding their tasks and more awareness with a specific functional concept same as self-efficacy.

Reviewing previous researches show that the effect of awareness of management tasks on the self-efficacy of managers was less addressed in the literature. Therefore, the present study has focused on this subject. In other word, the main challenging subject for the authors is referred to "if having appropriate information by a sport manager regarding his/her management tasks could increase a sense of self confidence in him/her named as self-efficacy and consequently lead to better handling of the organization under his/her administration. 
According to above mentioned subjects, the present research has analyzed the awareness level of managers regarding their management tasks and managers' self-efficacy besides the relationship of managers' awareness of their management tasks with self-efficacy.

\section{Research Method}

The present research is applied regarding the purpose of the study and correlativedescriptive, the data gathering method is the survey. The statistical population includes all the managers and senior employees in the field of sport in the organizations and governmental non-governmental institutions of Isfahan city in the year 2014 (about 120 individuals). Among them, there are 89 men and 31 women. The number of sport managers of Isfahan city is shown in table 1 in terms of gender.

Table 1: Frequency Distribution of statistical community in terms of Gender

\begin{tabular}{|c|c|c|c|}
\hline Statistical Population & Total No. & Men & Women \\
\hline $\begin{array}{c}\text { Senior Managers and } \\
\text { Employees }\end{array}$ & 120 & 89 & $\mathbf{3 1}$ \\
\hline
\end{tabular}

The number of required samples according to the whole sample was obtained through random simple sampling method using Cohen and Cochran Formula as follow:

$n=\left(N \times t^{2} \times p \times q\right) \div\left(N \times d^{2}+t^{2} \times p \times q\right)$

$\mathrm{n}=\left(120 \times 1 / 96^{2} \times 0 / 5 \times 0 / 5\right) \div\left(120 \times 0 / 05^{2}+1 / 96^{2} \times 0 / 5 \times 0 / 5\right)$

Following items generally considered in above formula: Maximum Permissible Error (d) equal to $0 / 05$, confidence coefficient equal to $0 / 95, t=1 / 96$ and values of $p$ and $q$ equal to $0 / 5$ and community size $(\mathrm{N})$. Therefore, the number of calculated sample was determined from the total number of statistical community equal to 91 . Table 2 shows the distribution of statistical community frequency and the number of samples. 
Table 2: The Frequency Distribution of Statistical Community and the Number of Sample.

\begin{tabular}{|c|c|c|c|}
\hline Row & Name of Organization or Club & $\begin{array}{c}\text { Total } \\
\text { Number }\end{array}$ & $\begin{array}{c}\text { Sample } \\
\text { Size }\end{array}$ \\
\hline 1 & Education Dept- Isfahan City & 2 & 1 \\
\hline 2 & General Education Dept.- Isfahan Province & 4 & 3 \\
\hline 3 & General Dept. of Sport and Youth- Isfahan & 25 & 18 \\
\hline 4 & Peneral Dept. of Sport and Youth- Isfahan City & 10 & 8 \\
\hline 5 & Zob Ahan Sport Complex- Isfahan City & 20 & 17 \\
\hline 6 & Mobarakeh Steel Company- Isfahan City & 20 & 18 \\
\hline 7 & Cultural Sport Clubs- Isfahan City & 15 & 10 \\
\hline 8 & Bonyad Shahid- Isfahan City & 4 & 3 \\
\hline 9 & Army Sport- Isfahan City & 5 & 2 \\
\hline 10 & Agriculture Jihad, Isfahan City & 3 & 3 \\
\hline 11 & Isfahan University & 2 & - \\
\hline 12 & Army of the Guardians of the Islamic & 5 & 3 \\
\hline 13 & Revolution, Isfahan City & 4 & 3 \\
\hline 14 & Municipality of Isfahan City & 2 & 2 \\
\hline & Islamic Republic of Iran Broadcasting, Isfahan & 120 & 91 \\
\hline & Province & & \\
\hline & Total & 20 & 2 \\
\hline
\end{tabular}

The data were gathered in this study through the questionnaire of awareness level of management tasks and self-efficacy for each variable.

The questionnaire for awareness level of management tasks was designed according to research made questionnaire of Seyedian with 30 questions that evaluate the awareness level of management tasks in six aspects. Each aspect of this questionnaire has 5 multiple choice questions in forms of true and false answers. If each person choose a true answer for each question gets 1 score and if choose a false answer for each question gets 0 score, finally every individual gets a final score between 0 and 30 in this test. According to the scoring method and defining the weak, moderate and good levels for obtained scores in this test, the scale of this questionnaire was changed from nominal scale to interval scale. Table 3 shows different levels of obtained scores in this test. 
Table 3: Classification Table of Score Levels Related to the Awareness Level of Management Tasks

\begin{tabular}{|c|c|}
\hline Classification & Scores \\
\hline Weak & $10-0$ \\
\hline Moderate & $20-11$ \\
\hline High & $30-21$ \\
\hline
\end{tabular}

Weak: Awareness lower than normal level, Moderate: Awareness in normal level High: Appropriate awareness and higher than normal level.

Sherer standard questionnaire (1982) including 17 questions in Likert scale was used for testing the self-efficacy level and scoring of items is a score among 1 to 5 . Therefore, the minimum possible score is 17 and maximum possible score is 85 . Each participant should state his/her real feeling about each question by choosing one of the five answers in the questionnaire. This questionnaire measures the individual's beliefs regarding his/her abilities for overcoming on different circumstances. The questions with similar contents repeat more than one time, so that the stability level of answers of the participant be defined. The scores below than normal level shows the weak self-efficacy of the individual and scores in higher than normal level shows higher self-efficacy.

Table 4: Classification Table of Score Levels of Self-efficacy Test

\begin{tabular}{l|c|c|}
\cline { 2 - 3 } & Classification & Scores \\
\hline Weak & $\mathbf{1 7 - 4 0}$ \\
\hline Moderate & $\mathbf{4 1 - 6 3}$ \\
\hline High & $\mathbf{6 4 - 8 5}$ \\
\hline
\end{tabular}

In order to define the content and face validity, the questionnaires along with purposes of the study were provided to 10 professors in the field of sport management in the area of management and planning. They were asked to provide their comments. Then the necessary reformations were applied and the questionnaires were adjusted again.

The Cronbach's alpha test was used for testing the stability of awareness level questionnaires about management tasks and self-efficacy. Cronbach's alpha reflects the internal correlation between the questions of a test. For this purpose, 30 participants were selected and the relevant questionnaires were evaluated, then the Cronbach's alpha value was obtained. The obtained results have confirmed the stability and validity of the questionnaires. According to the Cronbach's alpha coefficient for the questionnaire, the awareness level about management tasks was obtained as 0/741, also the Cronbach's alpha coefficient for self-efficacy was obtained as 0/784 that is consistent with value of 0/86 reported by Sherer et al. and 0/88 reported by Azizi Abarghui in Iranian samples. 
Since the participants includes managers or senior employees of different institutions in charge of sport affairs in related institutions, so the researcher presented the questionnaires in person in times that they were free after required arrangements and gathered them after answering.

The analyzes of the present study was performed in descriptive level using distribution frequency tables, percentage, graph, average, standard deviation and in the inferential level using Kolmogorov-Smirnov test for testing the normalization of the distribution, Levene test for studying the arrangement status and homogeneity of variance, Pearson correlation coefficient tests defining the relationship between research variables, single variable t-test for comparison of the sample mean with supposed mean of the community for both variables (awareness level of management tasks and self-efficacy). The significance level in the present study was considered as 0/05. All the statistical works accomplishes by SPSS Software-V20.

\section{Results}

The awareness level questionnaire among sport managers of Isfahan city included 30 multiple choice questions and the total number of them was obtained through Spss software to describe the overall awareness level of managers about management tasks and were classified in weak (0-10), moderate (11-20) and high (21-30) levels. Table 5 and diagram 1 were obtained according to these classifications. The obtained results shows that most of managers (59\%) have moderate awareness about their tasks.

Table 5: Awareness Level of Management Tasks

\begin{tabular}{|c|c|c|}
\hline $\begin{array}{c}\text { Awareness Level of } \\
\text { Management Tasks }\end{array}$ & Frequency & $\begin{array}{c}\text { Frequency } \\
\text { Percentage }\end{array}$ \\
\hline Weak & 2 & $4 / 2$ \\
\hline Moderate & 49 & $0 / 59$ \\
\hline High & 32 & $6 / 36$ \\
\hline Total & 83 & 100 \\
\hline
\end{tabular}


Diagram 1: Awareness Level of Management Tasks in Sport Managers

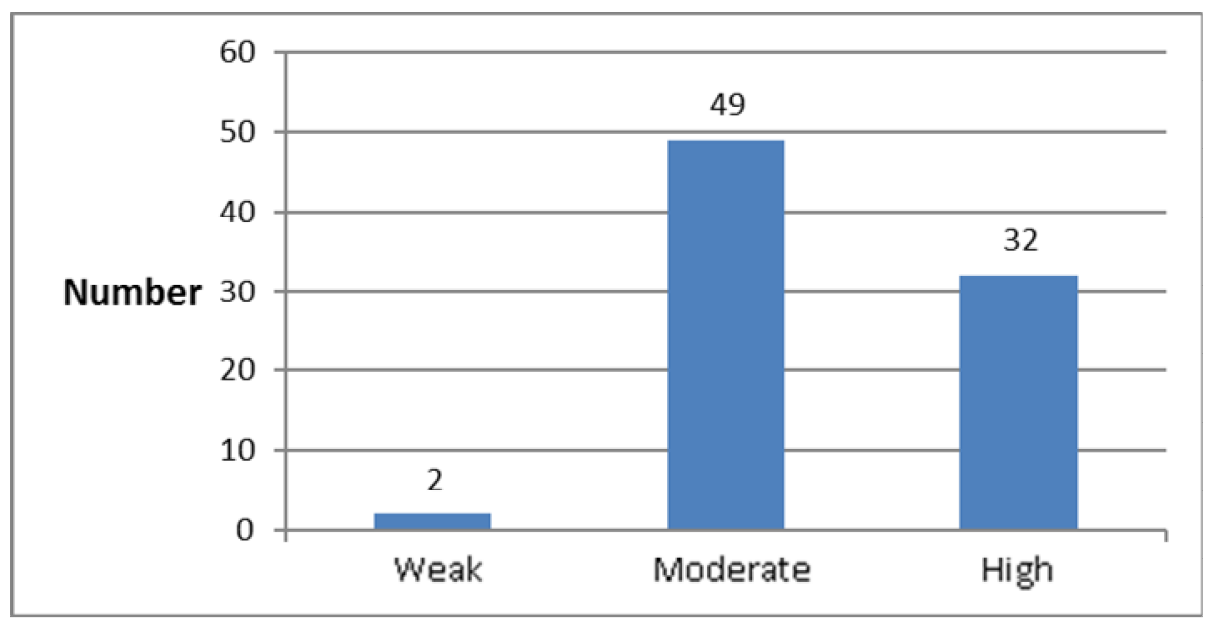

The questionnaire of self-efficacy level of sport managers included 17 multiple choice questions in Likert scale, that the total amount of them were obtained using Spss software to describe the overall self-efficacy level of sport managers and were classified in weak (17-40), moderate (41-63) and high (64-85) levels. Table 6 and diagram 2 were obtained according to these classifications. The obtained results shows that most of managers $(81.9 \%)$ have high self-efficacy and rest of them (18.1\%) have moderate self-efficacy.

Table 6: Self-efficacy Level of Managers

\begin{tabular}{|c|c|c|}
\hline Self-efficacy Level & Frequency & Frequency Percentage \\
\hline Weak & 0 & 0 \\
\hline Moderate & 15 & $18 / 1$ \\
\hline High & 68 & $81 / 9$ \\
\hline Total & 83 & 100 \\
\hline
\end{tabular}


Diagram 2: Self-efficacy Level in Sport Managers

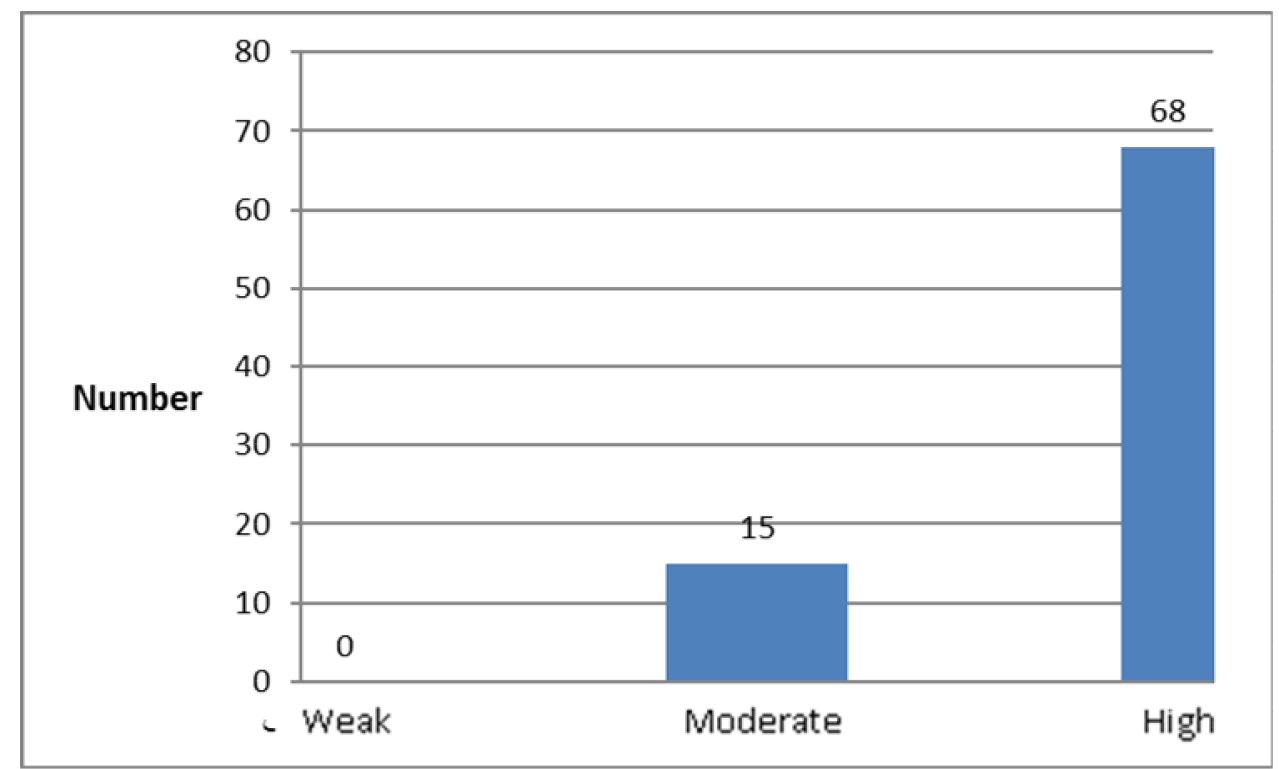

The data extracted from the answers of participants to the questions are provided descriptively in table (7). These findings show that the score range of planning, decision making, command, control and supervision and coordination was from 0 to 5 and for organization was from 1 to 5. Also, the score range of awareness level was from 6 to 27 and for self-efficacy was from 45 to 82 . The possible minimum and maximum score are defined for each variable in this table.

Table 7: Statistical Indicators of Awareness Level and Self-efficacy

\begin{tabular}{|c|c|c|c|c|c|c|c|c|}
\hline $\begin{array}{c}\text { Variable } \\
\text { Title }\end{array}$ & Planning & Organization & $\begin{array}{c}\text { Decision } \\
\text { Making }\end{array}$ & Command & Control & Cooperation & $\begin{array}{c}\text { Awareness } \\
\text { Of } \\
\text { Management } \\
\text { Tasks }\end{array}$ & $\begin{array}{c}\text { Self- } \\
\text { Efficacy }\end{array}$ \\
\hline Mean & $3 / 3$ & $3 / 28$ & $3 / 25$ & $3 / 55$ & $3 / 39$ & $2 / 42$ & $19 / 19$ & $68 / 16$ \\
\hline $\begin{array}{c}\text { Standard } \\
\text { Deviation }\end{array}$ & $0 / 997$ & $0 / 992$ & $1 / 228$ & $1 / 232$ & $1 / 296$ & $1 / 201$ & $3 / 877$ & $7 / 105$ \\
\hline Variance & $0 / 944$ & $0 / 984$ & $1 / 507$ & $1 / 517$ & $1 / 679$ & $1 / 442$ & $15 / 031$ & $51 / 122$ \\
\hline Mode & 3 & 3 & 4 & 4 & 4 & 2 & $15 / 62$ & $64 / 68$ \\
\hline $\begin{array}{c}\text { Possible } \\
\text { Min. }\end{array}$ & 0 & 0 & 0 & 0 & 0 & 0 & 0 & 17 \\
\hline $\begin{array}{c}\text { Possible } \\
\text { Max. }\end{array}$ & 5 & 5 & 5 & 5 & 5 & 5 & 30 & 85 \\
\hline Min. & 0 & 1 & 0 & 0 & 0 & 0 & 6 & 46 \\
\hline Max. & 5 & 5 & 5 & 5 & 5 & 5 & 27 & 82 \\
\hline
\end{tabular}


According to the Sig values obtained from single sample t-test, the hypothesis of equality of the mean of every aspect to 2.5 (the supposed mean) except the coordination aspect is rejected in all the items. Therefore, according to the results of above tables, the mean of five aspects of planning, organization, decision making, command and control in the community is higher than normal level. Also, the Sig values for awareness variable show that the awareness level is higher than moderate level among sport managers of Isfahan city.

Table 8: Comparison of Mean Score of Two Factors: Awareness Level with the Supposed Mean of the Statistical Community

\begin{tabular}{|c|l|l|l|l|l|l|c|}
\hline Factors & $\begin{array}{c}\text { Mean of } \\
\text { Differences }\end{array}$ & $\begin{array}{c}\text { Statistic } \\
\text { of t-test }\end{array}$ & $\begin{array}{c}\text { Freedom } \\
\text { Degree }\end{array}$ & $\begin{array}{c}\text { Testing } \\
\text { Amount }\end{array}$ & Sig & & $\begin{array}{c}\text { Bounds of } \\
\text { Confidence } \\
\text { Interval }\end{array}$ \\
\hline Planning & $7 / 323$ & 82 & $2 / 5$ & $0 / 001$ & $0 / 801$ & $0 / 58$ & $1 / 02$ \\
\hline Organization & $7 / 140$ & 82 & $2 / 5$ & $0 / 001$ & $0 / 777$ & $0 / 56$ & $0 / 99$ \\
\hline $\begin{array}{c}\text { Decision- } \\
\text { making }\end{array}$ & $5 / 586$ & 82 & $2 / 5$ & $0 / 001$ & $0 / 753$ & $0 / 48$ & $1 / 02$ \\
\hline Command & $7 / 794$ & 82 & $2 / 5$ & $0 / 001$ & $1 / 054$ & $0 / 79$ & $1 / 32$ \\
\hline Control & $6 / 227$ & 82 & $2 / 5$ & $0 / 001$ & $0 / 886$ & $0 / 60$ & $1 / 17$ \\
\hline Cooperation & $-0 / 594$ & 82 & $2 / 5$ & $0 / 554$ & $-0 / 78$ & $-0 / 34$ & $0 / 18$ \\
\hline $\begin{array}{c}\text { Awareness of } \\
\text { Management } \\
\text { Tasks }\end{array}$ & $9 / 827$ & 82 & 15 & $0 / 001$ & $4 / 193$ & $3 / 34$ & $5 / 04$ \\
\hline
\end{tabular}

According to the Sig value obtained from single sample t-test, the hypothesis of equality of the mean of self-efficacy to 51 (the supposed mean) is rejected. Therefore, according to the results of table (9), the self-efficacy level among sport managers of Isfahan city is higher than moderate level.

Table 9: Comparison of Mean Score of Self-efficacy with Supposed Mean of the Statistical Community

\begin{tabular}{|l|l|l|l|l|l|l|l|}
\hline Factors & $\begin{array}{c}\text { Statistics } \\
\text { of t-test }\end{array}$ & $\begin{array}{c}\text { Degree of } \\
\text { Freedom }\end{array}$ & $\begin{array}{c}\text { Testing } \\
\text { Amount }\end{array}$ & Sig. & \multicolumn{2}{|c|}{$\begin{array}{c}\text { Average of } \\
\text { Differences }\end{array}$} & \multicolumn{2}{|c|}{$\begin{array}{c}\text { Bounds of } \\
\text { Confidence } \\
\text { Intervals }\end{array}$} \\
\hline & & & & & & $\begin{array}{c}\text { Upper } \\
\text { Bound }\end{array}$ & $\begin{array}{c}\text { Lower } \\
\text { Bound }\end{array}$ \\
\hline $\begin{array}{l}\text { Self- } \\
\text { efficacy }\end{array}$ & $22 / 000$ & 82 & 51 & $0 / 001$ & $17 / 157$ & $15 / 61$ & $18 / 71$ \\
\hline
\end{tabular}

According to the results of table 10, the Sig value is equal to 0.001 and less than significant level (0.05), the null hypothesis stating that there is no significant relationship between 
awareness of management tasks with self-efficacy is rejected. It could be concluded that there is positive significant relationship between awareness level of sport managers of Isfahan city and their self-efficacy.

Table 10: The Relationship between Awareness Level of Management Tasks with Selfefficacy

\begin{tabular}{|l|c|c|c|}
\hline & Statistic of the Test & Sig & Significance Level \\
\hline Pearson Correlation & $0 / 391$ & $0 / 001$ & $0 / 05$ \\
\hline
\end{tabular}

\section{Discussion}

The results have shown that there is positive significant relationship between awareness levels of management tasks with self-efficacy. In other words, self-efficacy increases with increase of awareness level of management tasks among sport managers of Isfahan city. The research findings in this area are consistent with findings of Mokhtaripour (6), Seyedian (2), Potter (12), Dominic (9) and Lunenburg (10).

Self-efficacy refers to the beliefs or judgments of an individual toward his/her abilities in performing the tasks and responsibilities. So, if the person be aware of his/her assigned tasks and reveals his/her knowledge, his/her feeling and judgment about his/her abilities increase and the individual experience the self-worth feeling.

The perceived self-efficacy is effective on selection of the specific goals and also on implementing them. People with strong self-efficacy focus on promotion circumstances and overcome on obstructions and could control the environment and limitations with innovation and persistence (7).

\section{References}

1. Parhizkar K. (1973), Theories of Management. Tehran: Khoosheh Publications.

2. Seyedian S. (2011), The Study of Relationship Between Awareness of Management Tasks with Work Motivation and Self-efficacy among Managers of North Khorasan Province, Thesis of Master Degree, Management Faculty, Islamic Azad University, Mashhad Branch.

3. Alagheband, A. (1989), the Preliminaries of Educational Management, First Edition, Tehran: Payam-e Nour University Publications.

4. Alagheband, A. (2000), General Management, Fifth Edition, Tehran: Besat Publications.

5. Ghanavi, Gh. (1998), Organization and its Management, First Edition, Tehran: Termeh Publications.

6. Mokhtaripour, M. (2004) the Study of Educational Groups Managers' Tasks on the Efficiency of The Members of Scientific Boards of Isfahan University from the 
viewpoint of Scientific Board Members, The magazine of Management Knowledge, 65: 71-90.

7. Bandura A. 1997. Self efficacy: the exercise of control. New York: Freeman W H.

8. Bandura, A. 2000. Social cognitive theory: An agentic perspective. Annual Review of Psychology.52:1-26.

9. Dominic C. 2004. Human resource management practices, faculty efficiency and the impact on teaching performance and university effectiveness. http:lip.umi.com.

10. Lunenburg FC. 2011. Self- efficacy in the workplace: implications for motivation and performance. International Journal of Management, Business, and Administration. 14: 1.

11. Pajris S. 1996. From http: psychology. About. com

12. Potter L. 2003. How to improve teacher efficiency. Restion.Va.Eric. Record no.38911.

13. SueV M. 2012. The Use of kp.org and Self-Efficacy to Manage Chronic Conditions. Kaiser Foundation Health Plan, Inc. Pleasanton. 